\title{
Yoğun Bakım Ünitesindeki Hastanın Fiziksel Değerlendirmesinde Kavram Haritası Kullanılması
}

\author{
Using a Concept Map in the Physical Assessment of the Patient in the Intensive Care Unit
}

Gönül KARA SÖYLEMEZ ${ }^{1}$, Sevinç MEŞE², Hülya BULUT ${ }^{3}$

\begin{abstract}
ÖZ
Bireylerin mevcut sağllk durumunun ve sağlık durumuna yönelik risklerin değerlendirilmesi, bu değerlendirmelerin bireye özgü olması, hemşirelik bakımında fiziksel değerlendirme yöntemlerinin etkin kullanılması ile ilişkilidir. Fiziksel değerlendirme ile hastanın fizyolojik durumuna ilişkin objektif veriler elde edilmekle birlikte, hastanın sağlık öyküsü ile elde edilen subjektif veriler de doğrulanabilmektedir. Fiziksel değerlendirme ile bireye özgü bakım planlarının hazırlanması ve hemşirelik bakımının kalitesinin artırılması sağlanabilmektedir. Bu bağlamda yoğun bakım hemşireleri hemşirelik sürecinin tanılama aşamasında fiziksel değerlendirme yöntemlerinden sıklıkla yararlanmaktadır. Yoğun bakım hemşirelerinin bireyselleştirilmiş hasta bakım sonuçlarının kalitesini artırmak için, yoğun bakım ünitesindeki hastaların fiziksel değerlendirmesini etkili ve doğru yapmaları oldukça önemlidir. $\mathrm{Bu}$ amaç doğrultusunda hemşirelerin yoğun bakım gibi karmaşık ünitelerde hasta bakımını etkili ve doğru vermeleri için kavram haritalarının kullanması önemlidir. Kavram haritalarının hasta bakımında klinik karar verme, eleştirel düşünme ve iletişim becerilerini geliştirme gibi önemli etkiye sahip olduğu bilinmektedir. $\mathrm{Bu}$ derlemede fiziksel değerlendirmenin hemşirelik bakımında önemi vurgulanmakla birlikte, hemşirelere yoğun bakım hastalarının fiziksel değerlendirmesinde yol gösterecek ve bakımda kolaylık sağlayacak bilgilerin kavram haritasıyla sistematik bir formatta sunulması amaçlanmıştır.
\end{abstract}

Anahtar Kelimeler: Fiziksel Değerlendirme, Hemşire, Kavram Haritası.

\begin{abstract}
Evaluating the current health status of individuals and the risks related to their health status, the specificity of these evaluations to the individual is related to the effective use of physical assessment methods in nursing care. While objective data on the patient's physiological state can obtain with physical evaluation, it can also confirm subjective data obtained with the patient's health history. Therefore, with physical evaluation, can prepare individual-specific care plans, and nursing care quality can increase. In this context, intensive care nurses frequently use physical assessment methods at the diagnostic stage of the nursing process. Therefore, intensive care nurses need to make effective and correct physical evaluations of patients in the intensive care unit to increase individualized patient care results. For this purpose, nurses need to use concept maps to provide effective and accurate patient care in complex units such as intensive care. It knows that concept maps have essential effects such as clinical decision making, critical thinking, and improving communication skills in inpatient care. In this review, although the importance of physical assessment in nursing care emphasizes, it is aimed to present the information that will guide nurses to the physical evaluation of intensive care patients and provide convenience in care in a systematic format with a concept map.
\end{abstract}

Keywords: Physical Assessment, Nurse, Concept Map.

\footnotetext{
${ }^{1}$ Öğr. Gör. Gönül KARA SÖYLEMEZ, Cerrahi Hastalıkları Hemşireliği, Hatay Mustafa Kemal Üniversitesi Sağlık Bilimleri Fakültesi Hemşirelik Bölümü,gonulsoylemez11@gmail.com, ORCID:0000-0002-4840-1183

${ }^{2}$ Öğr. Gör. Sevinç MEŞE, Tıbbi Hizmetler ve Teknikler Bölümü, Yozgat Bozok Üniversitesi Sağlık Hizmetleri Meslek Yüksekokulusvncmesee@gmail.com, ORCID: 0000-0003-4635-9169

${ }^{3}$ Prof. Dr. Hülya BULUT, Cerrahi Hastalıkları Hemşireliği, Gazi Üniversitesi Sağlı Bilimleri Fakültesi Hemşirelik Bölümü, bhulya @ gazi.edu.tr, ORCID: 0000-0001-8241-989X
} 
Hemşirelik uygulamalarının temelini hemşirelik süreci oluşturmaktadır. Hemşirelik süreci, sağliklı ya da hasta birey ve ailenin bakım ihtiyaçlarının belirlenmesi, hemşirelik girişimlerinin planlanması, uygulanması, sonucun değerlendirilmesi gibi basamaklardan oluşan sistematik bir yaklaşımı temel almaktadır. ${ }^{1}$ Kişinin sağlığı ile ilgili bilginin toplanması ve bu bilginin analiz edilmesi "tanılama" aşaması ile başlar. Tanılama, kişinin mevcut ve geçmiş sağlik deneyimi ile ilgili bilgi toplamak ve hastalık durumunda baş etme yöntemlerinin belirlenmesi amaciyla sistematik olarak verilerin toplanması aşamasıdır. Tanılama ile hastanın sağlık durumuna yönelik kapsamlı veri elde edilebilmektedir. Hemşirelik bakımına yönelik kararların elde edilen verilere dayandırılması, bakım kalitesinin artırılmasında oldukça önemlidir. $^{2}$

Tanılama aşamasında verilerin toplanmasında fiziksel değerlendirmenin oldukça önemli olduğu belirtilmektedir. Fiziksel değerlendirme; kişinin baştan ayağa tüm sistemlere ilişskin durumunun, hemşirenin duyuları aracılığıyla ya da çeşitli araç ve gereçlerin yardımı ile muayene edilmesi olarak ifade edilmektedir., ${ }^{2,3}$ Fiziksel değerlendirmenin amacı, hastanın fizyolojik durumuna ilişkin objektif veri tabanı oluşturmak, sağlık öyküsü ile elde edilen sübjektif verileri doğrulamaktır. Bunun yanı sira hasta problemlerinin belirlenerek hemşirelik tanılarının oluşturulmasında, bakımın planlanmasında ve bakım sonuçlarının egerlendirilmesinde değerlendirme bulgularından yararlanılmaktadır. ${ }^{3} \mathrm{Bu}$ amaç doğrultusunda, hastanın genel görünüşü ve davranışları, yaşam bulguları, boy ve kilosu, derisi, tırnakları, baş-boyun, gözler, kulaklar, dil, burun, ekstremiteler, toraks, genital bölge değerlendirmesi yapilabilmektedir. Fiziksel değerlendirme yapilırken inspeksiyon, palpasyon, perküsyon ve oskültasyon teknikleri kullanılarak sistemler değerlendirilebilmektedir. ${ }^{1,3}$

\section{GİRIS}

Kritik hastaların bakımının yürütüldüğü yoğun bakım ünitelerinde fiziksel değerlendirmenin, hasta bakımında önemli olduğu belirtilmektedir. Yoğun bakım hemşirelerinin klinik hemşirelere oranla hasta izlem ve değerlendirme sıklığının daha fazla olduğu bilinmektedir. ${ }^{4}$ Cicolini ve arkadaşları (2015) yoğun bakım hemşireleri ile yaptıkları çalışmada, hemşirelerin inspeksiyon, palpasyon ve oskültasyon yöntemi ile gerçekleștirilen 30 fiziksel değerlendirme tekniğinden 26'sını rutin olarak

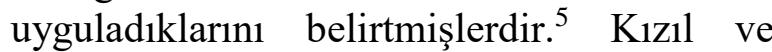
arkadaşlarının (2019) 102 yoğun bakım hemşiresiyle yaptıkları çalışmada ise, yoğun bakım hemşirelerinin hastaya bakım verdikleri zaman diliminde en az bir defa en fazla beş defa olmak üzere fiziksel değerlendirme yaptıkları belirtilmiştir. Ayrıca yoğun bakım hemşireleri, bakım planlarını fiziksel değerlendirmenin sonuçlarına göre düzenlediklerini ve hastanın bireyselleştirilmiş hemşirelik bakımına da fiziksel değerlendirme sonuçlarının katkı sağladığını ifade etmişlerdir. ${ }^{6}$

Etkin bir fiziksel değerlendirme ile yoğun bakım hemșireleri hastanın klinik durumundaki değişiklikleri hemen fark edebilir ve önlem alabilir. Örneğin; hemşire hastanın kalp atım hızı ve kalp sesinin oskültasyonu ile hasta kalp yetmezliğine girmeden önce tanı koyabilir. Akciğerlerin oskültasyonu ile akciğerlerdeki sekresyonvarlığının habercisi olan ralleri işitebilir ${ }^{4}$ Literatürde hemşirelerin fiziksel değerlendirme kapsamında olası risk durumlarını erken tanılayabileceği belirtilmektedir. Osborne ve arkadaşlarının (2015) 434 hemşire ile yaptıkları çalışmada hemşireler, fiziksel değerlendirme ile "distal nabızların alınamaması, kapiller geri dolumda gecikme, ciltte sıcaklık ve ödem bulgularının" kardiyovasküler hastalıklara yönelik belirtiler olabileceğini belirtmişlerdir. ${ }^{7}$ Alastalo ve arkadaşlarının (2017) yoğun bakım hemşirelerinin deneyimlerine yönelik yaptıkları çalışmada ise hemşireler, fiziksel değerlendirme ile hastanın akciğer ve bağırsak seslerini oskültasyon ile 
değerlendirebildiklerini, solunum ve monitör takibini yaptıklarını, hemodinamik parametreleri takip ettiklerini, asit-baz dengesine yönelik değerlendirmeler yapabildiklerini ve periferal nabızların değerlendirmesini yapabildiklerini ifade etmişlerdir. $^{8}$

Geçmişte geleneksel bakış açısı ile fiziksel değerlendirme hekim rolü olarak görülmekte, hemşirenin rol ve sorumlukları arasında kabul edilmemekte ve bu bağlamda hemşirelik eğitimlerinde fiziksel değerlendirmeye yer verilmemekteydi. Ancak hemşirelik rollerindeki gelişmeler ve yapılan çalışmalar fiziksel değerlendirmenin hemşirenin temel becerilerinden biri olduğunu göstermiştir. ${ }^{9}$ Hastanın kapsamlı fiziksel değerlendirmesi ile hasta bakım sonuçlarının kalitesinin arttığı belirtilmekte ve hemşirelerin fiziksel değerlendirme becerilerini hasta bakımına entegre etmeleri önerilmektedir. ${ }^{10}$

Günümüzde fiziksel değerlendirmenin sadece klinikte öğrenilen bir durum olmayıp, hemşirelik eğitiminin de ayrılmaz bir parçası olarak yürütülmesi gerektiği belirtilmektedir. ${ }^{11}$ Özellikle hastanın fiziksel değerlendirmesinin bir bütüncül yaklaşım içinde yapılması ve hemşirelerin analitik becerilerinin gelişmesi için farklı öğretim yöntemlerinin kullanılması gerektiği belirtilmektedir. $\mathrm{Bu}$ yöntemlerden en çok tercih edilen kavram haritalarıdır. Mayer (1989) kavram haritalarını; okuyuculara problem çözerken yaratıcı şekilde bilgi transfer etmeyi ve bilgileri uyumlu bir şekilde organize etmeyi sağlayan kısa ve özlü öğrenme şemaları olarak tanımlamıştır. Kavram haritası pratik kullanımı ve bilgide kalıcılık sağlaması ile hemşirelerin problem çözme ve eleştirel düşünme yeteneklerini geliştirerek, karmaşık hasta verilerini bakım sürecine entegre etmelerine yardımcı olmaktadir. Kavram haritası ile anahtar kavramlar seçilmekte, bu anahtar kavramlar alt kavram ve bilgiler ile çaprazlanmaktadır. $\mathrm{Bu}$ yöntem ile bir bütünün parçalarının nasıl analiz edileceği öğrenilmektedir. Örneğin ciltte hassasiyet, kızarıklık ve ödemin enfeksiyon belirtileri olduğunu öğrenmek gibi. $^{13}$
Vaka tartışmalarında, olgu sunumlarında ve hemşirelik bakım planlarında kavram haritasının kullanılmasinın önemi vurgulanmaktadır. Korkmaz ve arkadaşları (2011) tarafindan RespiratuarDistress Sendromu Tip 1 tanısı ile hastanede yatan yenidoğanın hemşirelik bakım planı, hemşirelik tanıları, komplikasyonlar, hasta öyküsü kavram haritası ile sunulmuştur. Vakanın kavram haritasıla sunumunun öğrenci hemşirelerin problem çözme becerisini ve eleştirel düşünme yeteneklerini kullanarak vakaya bütüncül baktıkları ifade edilmiştir. ${ }^{14}$ Ülseratif kolitin pediatrik bakımının kavram haritası ile açıklandığı bir diğer olgu çalışmasında ise hemşirelik bakımının kavram haritası ile açıklanmasının öğrenci hemşirelerin neden sonuç ilişkisini anlamalarına ve olguyu bütüncül olarak değerlendirmelerine katkı sağlayacağı ifade edilmiştir.

Ayrıca kavram haritalarının öğrenci hemşirelerin öğrenme sürecini kolaylaştıracağı vekavramlar arasındaki ilişkiyi görselleştirerek anlamlı öğrenmeyi sağlayacağı bildirilmiştir. ${ }^{15}$ Principal ve Shakuntala (2011) yaptıkları ön test son test kontrol gruplu bir çalışmada ise deney grubunda yer alan ögrenci hemşirelere kavram haritası kullanarak hemşirelik bakım planı hazırlama eğitimi verilmiştir ve deney grubunda kavram haritası kullanımının öğrenci hemşirelerin eleştirel düşünme becerilerini geliştirdiği bildirilmiştir. ${ }^{19}$

Yoğun bakım üniteleri, eleştirel düşünmenin zorunlu olduğu, tanı hatalarına yol açabilen bilişsel hatalara eğilimli yüksek riskli ortamlardır. Bu tanı hatalarının ortadan kaldırılması için yoğun bakım hemşirelerinin eleştirel düşünme becerilerinin geliştirilmesinden söz edilmektedir. Kavram haritaları kullanılarak tüme varımsal ve tümden gelimsel akıl yürütmeye temelli bakım, yoğun bakım hemşirelerini eleştirel düşünmeye teşvik etmektedir. ${ }^{17}$ Huang ve arkadaşlarının (2012) yaptıkları randomize kontrollü çalışmada, kavram haritası kullanarak hasta bakımını sürdüren hemşirelerin çalışma sonunda eleştirel düşünme becerilerinde gelişmeler olduğu 

(2014) yaptıkları bir çalışmada yoğun bakım hemşirelerinin klinik karar vermesinde kavram haritalarının önemli bir etkiye sahip olduğunu belirtmişlerdir. ${ }^{18}$

$\mathrm{Bu}$ bilgiler doğrultusunda bu makalede, hemşirelere yoğun bakım hastalarının fiziksel değerlendirmesinde yol gösterecek ve bakımda kolaylık sağlayacak bilgilerin kavram haritasıyla sistematik hale getirilmesi amaçlanmıştır. Yoğun bakım ünitesindeki

hastanın fiziksel sağlı̆̆ının değerlendirilmesinde kalp-damar sistemi, üriner sistem ve solunum sisteminin değerlendirilmesi Şekil-1'deki kavram haritasında açıklanmış ve değerlendirme sonrası bazı hemşirelik girişimlerine de yer verilmiştir. Şekil 1'de görüldüğü gibi ilgili sistemlerin değerlendirilmesinde öncelikle sistemlere ait hastanın sağlık öyküsünün alınması ve ardından uygun fizik muayene yöntemleri kullanılarak hastanın değerlendirilmesi gerekmektedir.

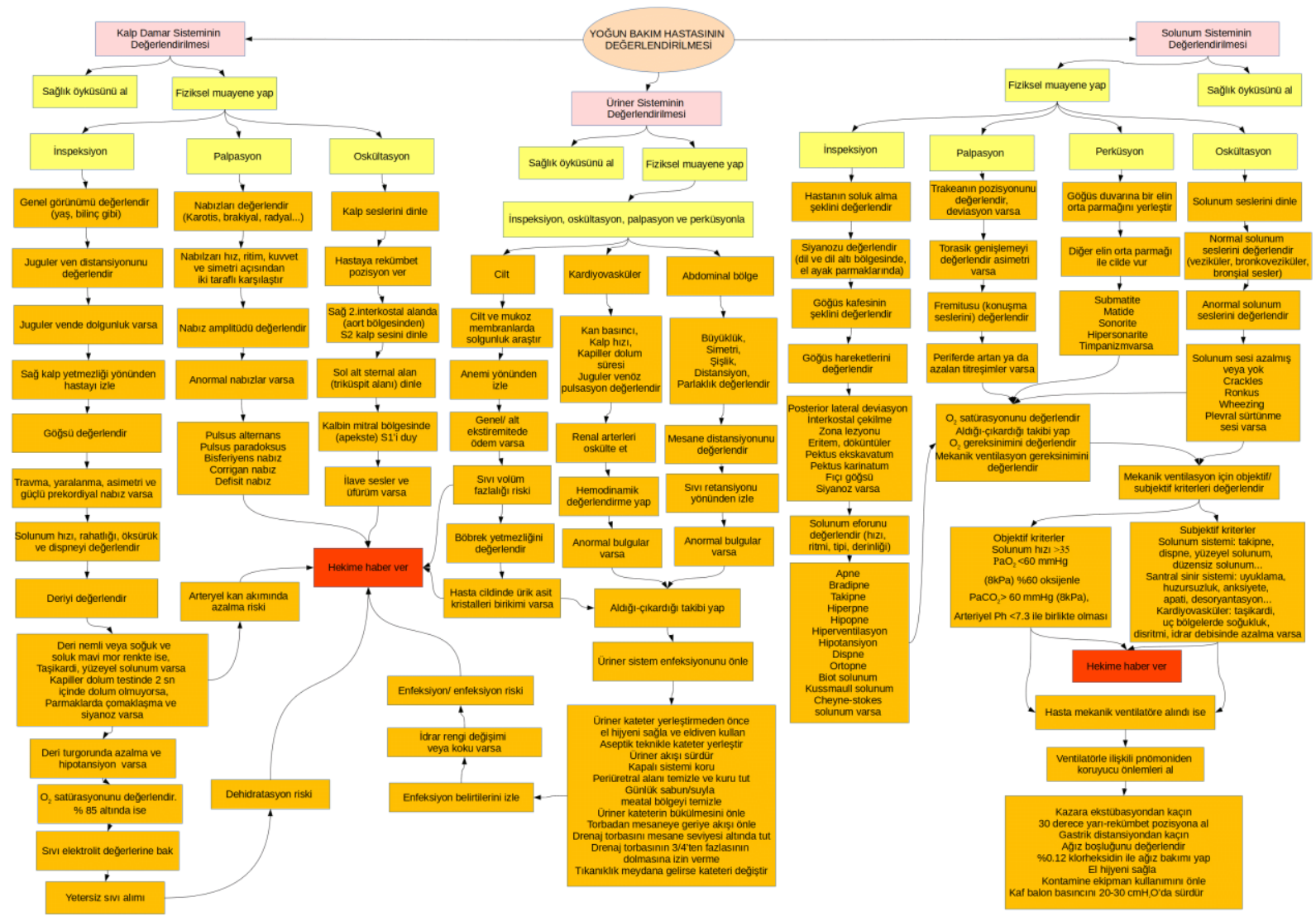

\section{Şekil 1. Kalp-Damar Sistemi, Üriner Sistem Ve Solunum Sisteminin Değerlendirilmesi}

$\mathrm{PaO}_{2}$ : Parsiyelarteryel oksijen basinc1 $\mathrm{PaCO}_{2}$ : Parsiyelarteryel karbondioksit basıncı

Şekil 2'deki kavram haritasında ise yoğun bakım ünitesindeki hastanın nörolojik, deri, beslenme, konstipasyon ve ağr1 değerlendirmesi açıklanmıştır. Ayrıca değerlendirme sonrası bazı hemşirelik girişimlerine de yer verilmiştir. Şekil 2'de görüldüğü gibi hastanın fiziksel değerlendirmesinde öncelikle sağlık öyküsünün alınması, uygun fizik muayene yöntemlerinin kullanılması ve uygun tetkiklerin yapılması gerekmektedir. 


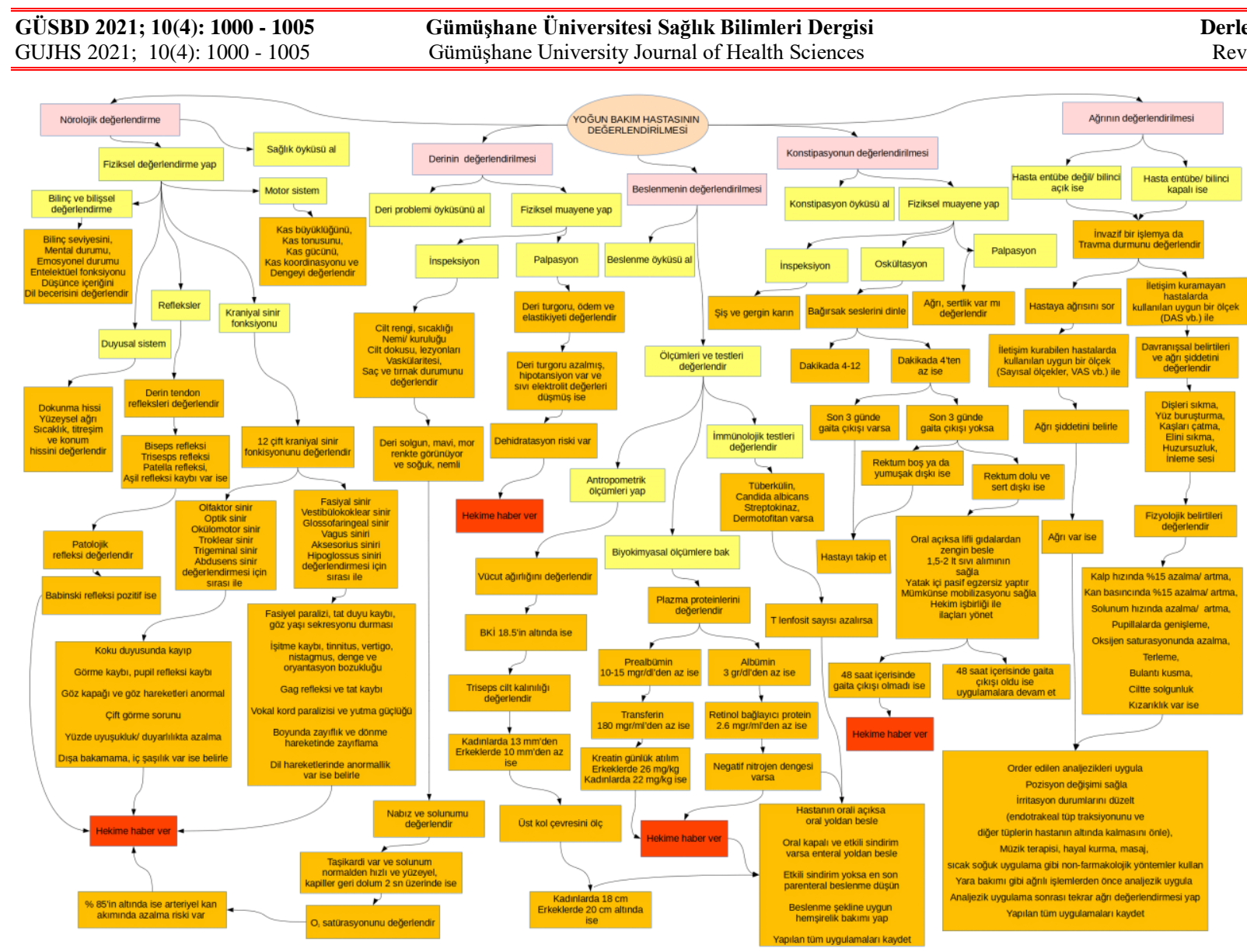

Şekil 2. Nörolojik, Deri, Beslenme, Konstipasyon Ve Ağrının Değerlendirilmesi

BKİ: Beden kitle indeksi DAS= Davranışsal ağrı skalası VAS= Visual analog skala

\section{SONUÇ VE ÖNERILER}

Sonuç olarak, yoğun bakım ünitesinde hastanın fiziksel değerlendirmesi oldukça önemlidir. Fiziksel değerlendirme ile yaşamı tehdit eden olası bir sağlık sorununun erken dönemde belirlenmesi sağlanabilmektedir. Yoğun bakım hemşirelerinin klinik hemşirelere oranla daha sik fiziksel değerlendirme yaptıkları bilinmektedir. Yoğun bakım hemşireleri fiziksel değerlendirme ile hastanın fizyolojik durumuna ilişkin veriler toplamakta, hemşirelik tanıları belirlemekte ve hasta bakım sonuçlarına katkı sağlamaktadır. Yoğun bakım hemşirelerinin, hastanın fiziksel değerlendirmesinde kavram haritası kullanması, hemşirelerin eleştirel düşüncelerinin geliştirilmesinde, bireyselleştirilmiş hasta bakım sonuçlarının kalitesinin arttırılmasında ve tanı hatalarının ortadan kaldırılmasında oldukça önemlidir. $\mathrm{Bu}$ nedenle kavram haritaları ile hasta bakımının verilmesi ve sonuçlarını ortaya koyan çalışmaların yapılması önerilmektedir. 


\section{KAYNAKLAR}

1. Birol, L. (2002). Hemşirelik Süreci. İzmir: Etki Matbaacıllk Yayıncilık.

2.Eyüboğlu, G. ve Çalışkan N. (2019). "Hemşirelerin Fiziksel Değerlendirme Becerilerini Kullanmalarındaki Engeller". Gümüşhane Üniversitesi Sağlık Bilimleri Dergisi, 8 (2), 57-61.

3. Olgun, N. ve Tosun, N. (2017). Fiziksel Değerlendirme ve Klinik Karar Verme. In: Editör F.E. ASLAN (Ed.). Sağlığın Değerlendirmesi ve Klinik Karar Verme (s.43-67). Ankara: Özyurt Matbaacilık.

4. Doğdu, A. K, Ergezen, F. D. ve Kol, E. (2019). "Yoğun Bakımda Hemşirelerin Kullandığı Hasta Değerlendirme Yöntemleri: Teknoloji ve Fiziksel Muayene Kullanımı". Yoğun Bakım Hemşireliği Dergisi, 23 (2), 102-106.

5. Cicolini, G, Tomietto, M, Simonetti, V, Comparcini, D, Flacco, M. E, Carvello, M. and Manzoli, L. (2015). "Physical Assessment Techniques Performed by Italian Registered Nurses: A Quantitative Survey”. Journal of Clinical Nursing, 24 (23-24), 3700-3706.

6. Kızıl, H, Altıntop, İ. ve Akyol, Y. E. (2019). "Hemşirelerin Bireyselleştirilmiş Bakımda Fiziksel Muayene Yöntemlerini Kullanma Durumlarının İncelenmesi”. Yoğun Bakım Hemşireliği Dergisi, 23 (3), 131-139.

7. Osborne, S, Douglas, C, Reid, C, Jones, L, andGardner, G. (2015). "The Primacy of Vital Signs-Acute Care Nurses' and Midwives' Use of Physical Assessment Skills: A Crosssectional Study". International Journal of NursingStudies, 52 (5),951-962.

8. Alastalo, M, Salminen, L, Lakanmaa, R. L. AndLeino-Kilpi, H. (2017). "Seeing Beyond Monitors Critical Care Nurses' Multiple Skills in Patient Observation: Descriptive Qualitative Study". Intensive and Critical Care Nursing, 42, 80-87.

9. West, S.L. (2006). "Physical Assessment: Whose Role Is It Any Way?’. Nursing in Critical Care, 11 (4), 161-167.

10. Zambas, S. I, Smythe, E. A,andKoziol-Mclain, J. (2016). “The Consequences of Using Advanced Physical Assessment Skills in Medicaland Surgical Nursing: A Hermeneutic Pragmatic Study". International Journal of Qualitative Studies on Healthand WellBeing, 11(1), 32090.

11.Lesa, R, and Dixon, A. (2007). "PhysicalAssessment: Implications for Nurse Educators and Nursing Practice". International Nursing Review, 54 (2), 166-172.

12. Mayer, R.E. (1989). "Models for Understanding”. Rev Educ Re $59,43-64$

13. Gul, R. B, andBoman, J. A. (2006). "ConceptMapping: A StrategyforTeachingandevaluationInNursingEducation".

NurseEducationInPractice, 6(4), 199-206.

14. Korkmaz, Z, Avc1, Ö, Tosun, Ö, Uslu, N, Erdem, E. ve Bayat, M. (2011). "Klinik Uygulamada Kavram Haritası Kullanımı: RespiratuarDistress Sendromu (RDS)". Sağlık Bilimleri Dergisi, 20 (3), 235-39.

15. Gümüș, M, Yaz, Ș.B. ve Șenol, S. (2020). "Ülseratif Kolitin Pediatrik Bakımı ve Kavram Haritası”. GÜSBD, 9 (3), 318-323.

16. Huang, Y. C, Chen, H. H, Yeh, M. L, and Chung, Y. C. (2012). "Case Studies Combined with or Without Concept Maps Improve Critical Thinking in Hospital-Based Nurses: A RandomizedControlled Trial". International Journal of Nursing Studies, 49 (6), 747-754.

17. Hayes, M. M, Chatterjee, S, and Schwartzstein, R. M. (2017). "Critical Thinking in Critical Care: Five Strategies to Improve Teaching and Learning in the Intensive Care Unit". Annals of the American Thoracic Society, 14 (4), 569-575.
18. Akbari, F.D, Mofrad, M.N, and Dabirian, A. (2014). "The Effect of Concept Mapping on Clinical Decision Making Skills of ICU Nurses”. Al AmEen J Med Sci, 7 (4), 312-315.

19. Principal, V. and Shakuntala, B.S. (2011). ConceptMapping-An Effective Tool To Promote Critical Thinking Skills among Nurses. Nitte University Journal of Health Science, 1 (4), 21-26. 